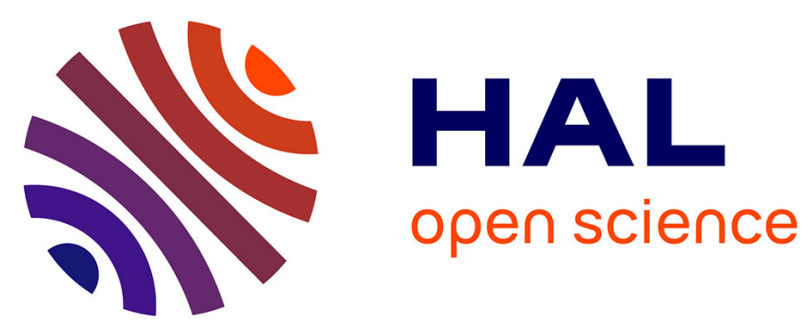

\title{
Viability of Magazines for Stimulating Social Interactions in Nursing Homes
}

\author{
Valentina Caforio, Marcos Baez, Fabio Casati
}

\section{To cite this version:}

Valentina Caforio, Marcos Baez, Fabio Casati. Viability of Magazines for Stimulating Social Interactions in Nursing Homes. 16th IFIP Conference on Human-Computer Interaction (INTERACT), Sep 2017, Bombay, India. pp.72-81, 10.1007/978-3-319-67687-6_6 . hal-01717198

\section{HAL Id: hal-01717198 \\ https://hal.inria.fr/hal-01717198}

Submitted on 26 Feb 2018

HAL is a multi-disciplinary open access archive for the deposit and dissemination of scientific research documents, whether they are published or not. The documents may come from teaching and research institutions in France or abroad, or from public or private research centers.
L'archive ouverte pluridisciplinaire HAL, est destinée au dépôt et à la diffusion de documents scientifiques de niveau recherche, publiés ou non, émanant des établissements d'enseignement et de recherche français ou étrangers, des laboratoires publics ou privés. 


\title{
Viability of Magazines for Stimulating Social Interactions in Nursing Homes
}

\author{
Valentina Caforio, Marcos Baez, and Fabio Casati \\ University of Trento, Italy, \\ \{valentina.caforio, marcos.baezgonzalez, fabio.casati\}@unitn.it
}

\begin{abstract}
Social isolation and loneliness have a strong negative impact on health and happiness. The correlation is present at all ages, but the risk of loneliness and isolation is particularly high in later life and when transitioning to residential care settings, where keeping in touch with the family, making new friends and integrating with the community in a new social context can be very challenging. In this note we report on our preliminary studies on the opportunity and feasibility of using custom, printed magazines for increasing feelings of connectedness and promoting meaningful interactions in nursing homes. The content and layout for the magazine are generated in an automatic or semi-automatic way and emphasize aspects that could lead to discovering connections or starting conversations. Initial findings point to the potential for such a magazine and lead to content guidelines that we elaborate in the paper.
\end{abstract}

Keywords: Older Adults, Nursing Homes, Social Interactions, Loneliness.

\section{Introduction}

Social isolation and loneliness are among the most dangerous and widespread diseases of modern times. Ample and concordant literature points to the lack of quality social interactions as a cause for declining mental health, lower happiness, and increased mortality, where the increase is comparable with those of alcohol and obesity $[4,15,2]$.

Social interactions are also a key element in our well-being as we age and as we transition to long-term residential care $[17,3]$. In addition to the challenges posed by a new environment where we are often placed without much choice for alternatives, with age we tend to become more selective in our friendships $[10,9,11]$ and less capable of regulating emotions from unpleasant friendship experiences [6].

Several studies have dealt with social isolation in older adults, proposing technological solutions to address the problem. Caprani et al. [5] propose a reminiscence device aimed at stimulating conversations and creating bonds among nursing home $(\mathrm{NH})$ residents, but also at helping users living alone at home. A low-fidelity prototype was evaluated on physical abilities, but results regarding the creation and enhancement of social bonds are not reported. 
Santana et al. [14] devised a digital family newspaper aimed at supporting relationships between Mexican older adults and their younger relatives abroad. The newspaper is organized in sections, which can be populated by personal memories, anecdotes, events, pictures or videos uploaded by both young and old family members to maintain emotional closeness. In subsequent studies, the authors report that the system has been implemented and tested, with positive results regarding concept and perceived ease of use. The idea of sharing pictures in particular was well received, and the system was perceived as a possibility to enhance users' relationships [13].

Other solutions to enhance intergenerational family contacts include digital picture frames $[8,7]$ for older adults, showing pictures sent by their younger relatives to provide topics of conversation and updates about their lives, as well as to create family cohesion.

Inspired by these attempts, in this work we explore the needs and possibilities for promoting social interactions in NHs in Italy. We believe insights and analyses can be generalized to many countries, but each nation - and sometimes each region - has specific NH populations and patterns in terms of, for example, family visits and interactions. Specifically, we aim at understanding the potential of leveraging a customized magazine as a vehicle for promoting interactions, and what the characteristics of such a publication should be.

In this paper we report on the preliminary studies we conducted to determine the feasibility and potential of such a publication. Specifically, for a magazine to be viable, we need to understand i) if there is a friendship issue at all in NHs, ii) if we can count on the help of staff and family members to guide the reading of the magazine and, very importantly, if magazine reading is an activity that is compatible with the practices in NHs, iii) if the parties involved may have privacy concerns that would prevent us from collecting content, and iv) which content, if any, would make the magazine interesting and appealing, if any. We next report on our study methods and findings in this respect.

\section{Problem Analysis}

To analyze the feasibility and determine a preliminary information design for such a magazine, we worked with six NHs in Italy, where we ran observations, interviews and focus groups that we detail in the following.

\subsection{Methods}

To investigate the nature of relationships in $\mathrm{NHs}$ we organized a set of visits to perform i) ethnographic observations and ii) semi-structured interviews with the staff (including volunteers in charge of entertainment activities) and relatives. The visits were conducted in the spring and summer of 2016 and attended by at least three researchers to collect different perspectives and reduce the chances of researcher bias [16]. These studies add to preliminary findings on the situation of intergenerational interactions in NHs [1]. 
Afterwards, in April 2017, we ran a focus group with representatives of each stakeholder (NH directors, coordinators, activity professionals and family representatives) of six different $\mathrm{NHs}$, to discuss our initial findings and refine our insights. During the focus group, each participant was handed a card with a discussion topic and a specific finding. Each participant read aloud the topic and finding of her card, and the discussion was driven by the personal observations and experiences of each of the participants.

The observations were approved by the Ethical committee of "APSP Santo Spirito - Fondazione Montiel" of Pergine, Italy on the resolution of the 06/03/2016. The studies received ethical approval from University of Trento Committee on Research Involving Human Beings (Application N. 2017-003).

\subsection{Results}

The emergent themes from the observations and interviews are presented below, enriched with the discussions from the focus group:

Rather discouraging state of affairs for interactions. In most NHs, the staff reports that residents do not make friends, in part because of the concerns related to the efficiency of managing and running a $\mathrm{NH}$ with a tight budget, which is reported as sometimes getting in the way of relationships. For example, residents do not have the option of choosing their roommates, and the roommates also change quite often based on evolution in the health condition of the residents (in some NHs, different areas of the NH are dedicated to residents with different needs). Sometimes the division is in floors and, while there are common areas, the interaction among people living on different floors is less frequent. On the other hand, residents do seem to have the habit to sit with the same people during meals. It is not clear, however how such companies at lunch are formed and the friendship opportunities that this generates.

Facilitating interactions relies heavily on the Staff. In the focus group, a distinction was made by the participants between residents that are independent and cognitively able and those who are less so. Those independent have more opportunities to engage in social interactions, and need little help from the NH in this regard. Those who are less independent though - which are the large majority - do need help from the organization, and for this reason the NHs offer various animation activities. Still, facilitating bonds depends heavily on the capabilities and wiseness of the Staff in matching the residents and stimulating conversations.

Interactions with relatives are mostly centered around one family member. We learned that in all NHs the majority of residents have a person (typically the daughter) that comes very frequently to visit, often every day. Interactions with the rest of the family are much less frequent, and this is a source of frustration for the visiting family member, who often does what she can to involve the enlarged family. The focus group acknowledged that for logistic reasons the NHs interact with one reference person (usually the family member most involved) and this does not help in involving the larger family. 
Grandchildren were cited as a frequent source of joyful visits, though mostly young children visit. Several NHs organize events and projects with younger people to make them interact with older adults and help both parts benefit from intergenerational contacts. During the focus group, it was observed by the participants that it is easier to interact with them for small children, who are spontaneous and don't fear the interaction. Not the same for older children and teens, who are less at ease and find it more difficult to interact.

Interactions with family, peers and staff are important. We emphasize that while family contacts are important and family members contribute to life satisfaction, friends contribute to affect [12]. Participants of the focus group stressed that friendships with other residents and with the staff are also crucial to facilitate adaptation in the RSA environment. In response to a concern of a family member participating in the focus group, about her mother and her difficulties in the transition to residential care, other participants mentioned how bonds help residents perceive the $\mathrm{NH}$ as a home.

In relation to the above challenges, NHs have already some practices and initiatives that can be taken as starting points on which solutions could be built (see Figure 1, left side):

- Pictures and events from the past can be found in open and personal spaces (Figure 1A), which shows ongoing practices of reminiscence in the $\mathrm{NHs}$ and an interest from residents.

- Reading magazines and newspapers is a recreational activity performed in all NHs (Figure 1B), often with the help of staff and volunteers. Some NHs also act as daily recreational centers for a part of the population, in that case magazines are read daily.

- Posters and boards display pictures of the activities (Figure 1C), as a way of informing visitors of the activities.

- In some NHs there are computers intended for Skype calls (Figure 1D) for residents who have relatives far away, but it turns out they are not used much or not at all, also because of the lack of dedicated personnel to assist residents and organize calls. Some NHs have Internet points and allow their residents to use the computers, however residents are generally not digitalized.

- Memories from family members are treasured by residents (Figure 1E), and are often drivers in conversations, even with the Staff.

In what follows we take these insights and opportunities into the design of a tool for promoting interactions among residents, family members and Staff, building on existing practices and mediums that are already widely used and accepted by our target population.

\section{Customized Magazines Promoting Interactions}

The studies and observations oriented us toward the idea of leveraging a traditional and accepted method for interaction, that is, a printed magazine ${ }^{1}$ (called

\footnotetext{
${ }^{1}$ Print-ready version of a prototype https://goo.gl/a3HSyu
} 
the Collegamenti Magazine - "connections" in Italian) as both a recreational activity and a vehicle to promote interactions. Reading a magazine is not only something people are already used to, but something $\mathrm{NH}$ residents regularly do and that is already integrated within the $\mathrm{NH}$ processes.
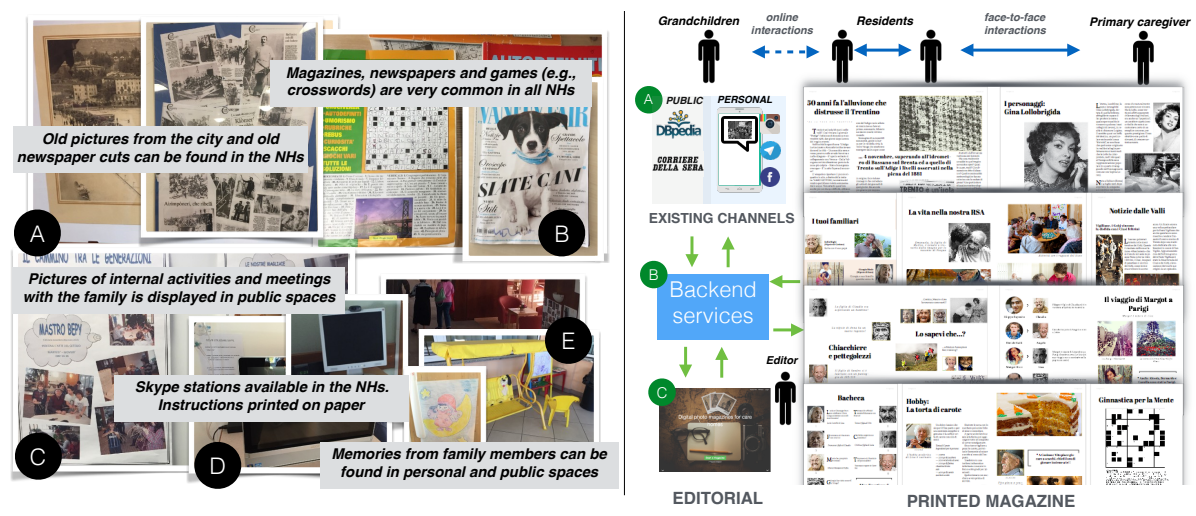

Fig. 1. Left: Collage of pictures from observations. Right: Magazine generation process.

The main idea is to include in the magazine personalized content contributed mainly by family members, and organized in such a way that it motivates interactions among residents and between residents and family members. In other words, we use technology to redesign the content over a traditional interaction method and to make the whole production cycle practical and sustainable (see Figure 1), with the goal of keeping residents up-to-date with the life of the family and of creating topics of conversations between older adults, their younger relatives and their peers.

\subsection{Magazine Content}

The above opportunities can be leveraged by collecting interesting content about the past or about readers themselves, with the aim of providing a common ground readers can relate to, which can turn into new topics of conversation and opportunities for interaction. With this goal in mind, and building on our preliminary observations, we propose the following types of section:

- Reminiscing: Sections describing news, facts or people from the past. The goal is to create new topics of conversations and stimulate the cognitive and social abilities.

- Bulletin boards: Announcements and facts from residents and family. The goal of these sections is to create topics of conversations but also to provide a fun and interesting read for the residents, and for the larger family reading from home. 
- News from relatives: Photos and activities collected from social media and other channels, to keep the residents informed and stimulate conversations.

- Life in the NH: Future and past NH events, with pictures and descriptions. The goal is to keep the larger family informed (and involved) and to create a new communication channel between the $\mathrm{NH}$ and the external world.

- From the community: News and obituaries to keep residents informed about what happens outside the $\mathrm{NH}$, and to stimulate conversations.

- Hobbies: Articles about hobbies residents are interested in. The goal is to offer an interesting read that can stimulate conversations among residents.

- Connections: Sections showing what residents have in common. The goal is to help them know each other, stimulate conversations and shared activities.

The content is organized in sections using a design inspired by magazines for our target population, putting emphasis on pictures, showing connections among residents starting from the content and providing conversation triggers. This is important because, as we expect family members and volunteers to drive the reading sessions, we still enable residents - to the possible extent — to recognize the content and engage in the conversations.

\subsection{Production Process}

To make the process for generating the magazine sustainable, we devise an architecture and algorithms that could support increasing levels of human involvement in collecting, selecting and organizing the magazine content. As seen in Figure 1 (Right), this is done by (A) reusing existing channels and content, (B) using back-end services and matchmaking algorithms based on ranking and (C) through an editorial tool for managing the magazine generation process. We stress that automation is very important as the generation requires the involvement of relatives and NH staff. Notice that professionals and relatives are indeed the persons we expect to be the main drivers of magazine reading, more so than the residents themselves, as newspaper reading is typically guided.

\section{Early Evaluation}

We performed two preliminary evaluations with relatives and staff members to first validate the concept of the magazine and its fit in the $\mathrm{NH}$ processes, and then to look specifically at each section. The relatives are heavily involved in our design and validation process because they are a central element in the life of a resident, and, given that they visit very frequently, they can also act as catalysts for interactions as well as help in the reading activities. In this sense, they are part of our population of target readers.

\subsection{Concept Validation with Relatives and NH Staff}

Methods. Two researchers conducted semi-structured interviews with the relatives of 5 residents from two NHs, and with $2 \mathrm{NH}$ professionals responsible 
for the animation activities. The interviews took place inside the NHs and were done by first showing the magazine prototype and then explaining the concept with a storyboard. The objective was to obtain general feedback on the idea of the magazine and its applicability, in particular regarding its potential to create social interactions, to identify possible barriers, but also on the possibility to integrate it in the entertainment activities of the $\mathrm{NH}$.

Results. Professionals rated the magazine positively, stating that i) it can be beneficial for residents' social relationships, as it makes them feel at the center of the attention, and that ii) even reading the magazine individually represents a form of social interaction, because it will make them more aware of each other. Importantly, professionals stated that the magazine can be integrated in the entertainment activities, and even proposed collaborative editing of the content.

One of the professionals mentioned the positive potential of the artifact even when residents already have friends, perceiving it also as a communication channel between the NH and the outer world. Feedback on the look and feel was positive but scant: essentially the staff assessed it positively citing the importance of large text and big images, as well as the quantity of the images, which were evaluated as engaging.

Regarding the feedback collected from relatives, one of the interviewees mentioned a possible barrier of refusal in the resident, due to physical impairments (poor sight). One of them mentioned that it could work more as a communication channel with those relatives who cannot visit often, which is indeed a main goal of the magazine. Interviewees did not think there would be a privacy concern for their children or grandchildren, as the information and pictures shown about them are generic and not intimate.

\subsection{Content Validation with Different Stakeholders}

Methods. The magazine was shown in a focus group with 9 representatives of stakeholders, including directors, coordinators and representatives of the relatives. We presented the concept and handed them copies of the artifact to browse. We went through the sections with them: we explained their content, how they were created and their objectives. Then, participants were asked to quantify on a 5-point Likert scale whether they believed each section achieved its objectives or not, also discussing their opinions with the group.

Results. The magazine had very positive feedback, with an average score of 4.1 (Min: 3.6, Max: 4.7). The results about each section are summarized below.

- Reminiscing (avg: 4.2). Participants agree that past memories are a recurrent topic in $\mathrm{NH}$ and have the potential to spark conversations.

- Bulletin boards (avg: 3.7). Announcements, facts and "gossips" were referred as of interest in the community, though on the specific case of gossips the consensus was that it should be consulted with the resident (or family). 
- News from relatives (avg: 3.6). While participants agreed on the potential of these sections, they were concerned about the information automatically collected, suggesting to agree with the relatives beforehand on what type of information should and should not be disclosed with the resident.

- Life in the NH (avg: 4.3). Participants praised that this content would support some of the internal efforts to reach the larger family.

- From the community (avg: 4.3). News from the community are also a recurrent topic, though contrasting views were shared on whether to add obituaries. While it was considered sad by some participants, it was stressed that residents do check this section in newspapers.

- Hobbies (avg: 4.7). This section was very well received, participants stressing the interest in maintaining and discussing hobbies. This could also help in orienting animation activities and co-participation.

- Connections (avg: 3.9). This was well received, especially highlighting common aspects and featuring life stories, but it was pointed out that birthdays (part of this category) are not something residents are always happy to share.

On the concept of the magazine per se, it was generally agreed that a printed, "traditional" magazine can be a good solution for the target population in NHs. One participant mentioned that "A printed magazine would help us record the history of the NH, a history we can revisit at any time". However, a digital version was also considered useful especially for displaying the latest updates.

In general, the feedback from directors, coordinators and family members tells us that the magazine structure and content has the potential to meet the objectives and be integrated into the practices of the NHs. However, they need to be personalized and calibrated on contexts and needs of residents and families.

\section{$5 \quad$ Findings and Future Work}

The studies we performed indicate that there is a significant portion of cognitively healthy individuals that reside in the $\mathrm{NH}$ for relatively long periods of time and that do not make friends. The studies also indicate that a physical, printed magazine oriented towards encouraging interactions fits into the $\mathrm{NH}$ processes and is accepted by the NH staff (otherwise it would be very hard to have an impact). The frequent presence of a family member on site can also facilitate the reading activities. Finally, interviews with staff and family members were insightful in identifying and validating content and structure. This enables us to tailor the design so to maximize the effect of the magazine. This is important because studies in NHs are often challenging and potentially distressing, so background work is essential. Forthcoming work involves the magazine production (with actual content) and distribution in the NHs.

Acknowledgements. This project has received funding from the EU Horizon 2020 research and innovation programme under the Marie Skodowska-Curie grant agreement No 690962. This work was also supported by the "Collegamenti" project funded by the Province of Trento (l.p. n.6-December 13rd 1999). 


\section{References}

1. Baez, M., Dalpiaz, C., Hoxha, F., Tovo, A., Caforio, V., Casati, F.: Personalized persuasion for social interactions in nursing homes. arXiv preprint arXiv:1603.03349 (2016)

2. Berkman, L.F., Syme, S.L.: Social networks, host resistance, and mortality: a nineyear follow-up study of alameda county residents. American journal of Epidemiology 109(2), 186-204 (1979)

3. Bradshaw, S.A., Playford, E.D., Riazi, A.: Living well in care homes: a systematic review of qualitative studies. Age and ageing p. afs069 (2012)

4. Brummett, B.H., Barefoot, J.C., Siegler, I.C., Clapp-Channing, N.E., Lytle, B.L., Bosworth, H.B., Williams Jr, R.B., Mark, D.B.: Characteristics of socially isolated patients with coronary artery disease who are at elevated risk for mortality. Psychosomatic Medicine 63(2), 267-272 (2001)

5. Caprani, N., Dwyer, N., Harrison, K., O'Brien, K.: Remember when: development of an interactive reminiscence device. In: CHI'05 Extended Abstracts on Human Factors in Computing Systems. pp. 2070-2073. ACM (2005)

6. Charles, S.T., Leger, K.A., Urban, E.J.: Emotional experience and health: What we know, and where to go from here. (2016)

7. van Dijk, B., Dadlani, P., van Halteren, A., Biemans, M.: Life changes, connection stays: photo sharing and social connectedness for people with special needs. In: Proceedings of the 28th Annual European Conference on Cognitive Ergonomics. pp. 135-142. ACM (2010)

8. Jeurens, J., van Turnhout, K., Bakker, R.: Family in focus: On design and field trial of the dynamic collage [dc]. Creating the Difference p. 36 (2014)

9. Lang, F.R.: Endings and continuity of social relationships: Maximizing intrinsic benefits within personal networks when feeling near to death. Journal of Social and Personal Relationships 17(2), 155-182 (2000)

10. Lang, F.R., Carstensen, L.L.: Close emotional relationships in late life: further support for proactive aging in the social domain. Psychology and aging 9(2), 315 (1994)

11. Lang, F.R., Carstensen, L.L.: Time counts: future time perspective, goals, and social relationships. Psychology and aging 17(1), 125 (2002)

12. Pinquart, M., Sorensen, S.: Influences of socioeconomic status, social network, and competence on subjective well-being in later life: a meta-analysis. Psychology of Aging 15(2) (2000)

13. Rodríguez, M.D., Gonzalez, V.M., Favela, J., Santana, P.C.: Home-based communication system for older adults and their remote family. Computers in Human Behavior 25(3), 609-618 (2009)

14. Santana, P.C., Rodríguez, M.D., González, V.M., Castro, L.A., Andrade, Á.G.: Supporting emotional ties among mexican elders and their families living abroad. In: CHI'05 Extended Abstracts on Human Factors in Computing Systems. pp. 2099-2103. ACM (2005)

15. Seeman, T.E., Berkman, L.F., Blazer, D., Rowe, J.W.: Social ties and support and neuroendocrine function: the macarthur studies of successful aging. Annals of Behavioral Medicine (1994)

16. Taylor, S., Bogdan, R., DeVault, M.: Introduction to Qualitative Research Methods, 4th edition. Publisher: Wiley (2016)

17. Thomas, W.H.: Life worth living: How someone you love can still enjoy life in a nursing home: The Eden Alternative in action. Publisher: VanderWyk\&Burnham (1996) 